\title{
Alunos com deficiência intelectual e aprendizagem significativa: uma sequência didática sobre o tema - coronavírus
}

Students with intellectual disabilities and significant learning: a teaching sequence on the theme - coronavirus

Estudiantes con discapacidad intelectual y aprendizaje significativo: una secuencia didáctica sobre el tema - coronavirus

Cristiane Hammel

Mestra pela Universidade Estadual do Centro-Oeste, Guarapuava, PR, Brasil

E-mail: cris.hammel@yahoo.com ORCID: https://orcid.org/0000-0001-6717-9971

Sandro Aparecido dos Santos

Doutor pela Universidade Estadual do Centro-Oeste, Guarapuava, PR, Brasil

E-mail: sandrosantos@unicentro.br ORCID: https://orcid.org/0000-0002-5724-7499

Ricardo Yoshimitsu Miyahara

Doutor pela Universidade Estadual do Centro-Oeste, Guarapuava, PR, Brasil

E-mail: rmiyahara@unicentro.br ORCID: https://orcid.org/0000-0003-4639-2380

Recebido em 19 de setembro de 2020

Aprovado em 18 de dezembro de 2020

Publicado em 20 de janeiro de 2021

\section{RESUMO}

O presente artigo vai relatar o planejamento, desenvolvimento e aplicação de uma sequência didática no formato de Unidade compartilhada de Ensino Potencialmente Significativa (UcEPS), uma variação da Unidade de Ensino Potencialmente Significativa (UEPS), sobre o tema Coronavírus. Esta alternativa diferenciada justifica-se pelo fato de tratar-se de um trabalho interdisciplinar, ou seja, o compartilhamento refere-se a abordagem do tema por mais de uma disciplina. A metodologia utilizada foi de cunho qualitativo. Os alunos que participaram deste trabalho frequentam a Escola Estadual na modalidade de Educação Especial Emílio Mudrey, na cidade de Turvo, no interior do estado do Paraná, são dezoito alunos de turmas daEJA (Educação de Jovens e Adultos). O objetivo principal foi verificar a pertinência da utilização desse tipo de sequência didática que, intrinsecamente oportuniza a aprendizagem significativa através dos oito passos nela previstos e, se foi possível verificar indícios dessa aprendizagem nos alunos. O texto é enriquecido com a fundamentação teórica necessária para subsidiá-lo, dessa forma serão tratados assuntos como deficiência intelectual, sequência didática e aprendizagem significativa. Observou-se no findar da aplicação da UcEPS que a mesma produziu bons resultados e, que evidências de aprendizagem significativa puderam ser percebidos, podendo assim afirmar que este tipo de sequência tem potencial para ser considerada uma alternativa proveitosa para o ensino de alunos com deficiência intelectual.

Palavras-chave: Educação Especial; Deficiência Intelectual; Aprendizagem Significativa. 
http://dx.doi.org/10.5902/1984686X61983

\section{ABSTRACT}

This article will report the planning, development and application of a didactic sequence in the format of a Potentially Significant Shared Teaching Unit (PMsTU), a variation of the Potentially Significant Teaching Unit (PMTU), on the theme Coronavirus. This differentiated alternative is justified by the fact that it is an interdisciplinary work, that is, sharing refers to the approach of the theme by more than one discipline. The methodology used was of a qualitative nature. The students who participated in this work attend the State School in the Special Education modality Emílio Mudrey, in the city of Turvo, in the interior of the state of Paraná, are eighteen students from classes of YAE (Youth and Adult Education). The main objective was to verify the relevance of using this type of didactic sequence, which intrinsically provides meaningful learning through the eight steps provided in it and, if it was possible to verify evidence of this learning in students. The text is enriched with the theoretical foundation necessary to subsidize it, in this way, subjects such as intellectual disability, didactic sequence and significant learning will be treated. It was observed at the end of the application of PMsTU that it produced good results and that evidence of significant learning could be perceived, thus being able to affirm that this type of sequence has the potential to be considered a useful alternative for teaching students with intellectual disabilities.

Keywords: Special Education; Intellectual Disability; Meaningful Learning.

\section{RESUMEN}

Este artículo informará sobre la planificación, desarrollo y aplicación de una secuencia didáctica en el formato de una Unidad de Enseñanza Compartida Potencialmente Significativa (UEcPS), una variación de la Unidad de Enseñanza Potencialmente Significativa (UEPS), sobre el tema Coronavirus. Esta alternativa diferenciada se justifica por el hecho de que se trata de un trabajo interdisciplinario, es decir, compartir se refiere al abordaje del tema por más de una disciplina. La metodología utilizada fue de carácter cualitativo. Los alumnos que participaron de este trabajo asisten a la Escuela Estatal en la modalidad de Educación Especial Emílio Mudrey, en la ciudad de Turvo, en el interior del estado de Paraná, son dieciocho alumnos de las clases de EJA (Educación de Jóvenes y Adultos). El objetivo principal fue verificar la pertinencia de utilizar este tipo de secuencia didáctica, que intrínsecamente proporciona un aprendizaje significativo a través de los ocho pasos previstos en ella y, si fue posible verificar la evidencia de este aprendizaje en los estudiantes. El texto se enriquece con la base teórica necesaria para subvencionarlo, de esta forma se tratarán temas como discapacidad intelectual, secuencia didáctica y aprendizajes significativos. Se observó al final de la aplicación de la UEcPS que produjo buenos resultados y que se pudo percibir evidencia de aprendizajes significativos, pudiendo así afirmar que este tipo de secuencia tiene el potencial de ser considerada una alternativa útil para la enseñanza de estudiantes con discapacidad intelectual.

Palabras clave: Educación Especial; Discapacidad Intelectual; Aprendizaje significativo. 
http://dx.doi.org/10.5902/1984686X61983

\section{Introdução}

O maior desafio para professores que trabalham nas escolas de Educação Básica na modalidade de Educação Especial para pessoas com deficiência intelectual (DI) é preparar os alunos para independência e autonomia, para interagir socialmente e para o mundo do trabalho. Esta tarefa exige mais do que simplesmente cumprir os conteúdos acadêmicos do currículo formal, principalmente no que tange alunos com deficiência intelectual.

Infelizmente, são subestimadas as potencialidades dos alunos que frequentam as escolas especializadas e o ensino a eles oportunizado é frequentemente o que os mantém em um mundo de segregação focados nas suas fragilidades. As Unidades de Ensino Potencialmente Significativas (UEPS) possuem evidências científicas de proveitosa aplicação para alunos da Educação Básica como em: "O estudo do espectro eletromagnético: o ensino através de uma sequência didática - UEPS" e em "Uma UEPS com enfoque CTSA no ensino de Física: geração, produção e consumo de energia elétrica” ambos publicados em 2019 e, a partir dessas contribuições foi planejada e aplicada uma sequência didática para alunos da EJA em duas turmas, um total de 18 alunos.

Ao escolher as UEPS como alternativa que contribua para a aprendizagem significativa, foram considerados os passos nela previstos: planejamento, a escolha do tema ou conteúdo a ser trabalhado, depois, considerar os conhecimentos prévios dos alunos, reconhecendo um ponto de partida para então apresentar novos conhecimentos que devem interagir com os primeiros, oportunizar a reconciliação integrativa e buscar evidências de aprendizagem significativa.

A principal diferença entre a sequência didática aplicada, que chamamos de Unidade compartilhada de Ensino Potencialmente Significativa (UcEPS), das UEPS, é a interdisciplinaridade como condição indispensável, por isso incluímos o termo compartilhada. Nesse caso, a UcEPS além de privilegiar a aprendizagem significativa por meio dos passos nela previstos, também prima pela interdisciplinaridade.

Oferecer esse modelo de sequência didática é pensar no aluno com deficiência intelectual considerando sua capacidade de encontrar o subsunçor adequado, ressignificar e aprender novos conceitos. E por que não? Esse foi o questionamento ao cogitar propor a UcEPS à alunos com DI. Será possível verificar evidências de aprendizagem significativa? É pertinente elencar um tema e, a partir dele, abordar conteúdos de mais de uma disciplina? O resultado da UcEPS aplicada com tema "Coronavírus" mostrou-se bastante satisfatório. Considerando a condição única de cada aluno, pôde-se observar considerável assimilação 
http://dx.doi.org/10.5902/1984686X61983

de conteúdo e também de informações bastantes pertinentes em relação ao momento único a que estes alunos estavam expostos.

\section{Educação Especial para jovens e adultos: fragilidades e possibilidades}

Adentrar uma escola especializada no atendimento de alunos com necessidades educacionais especiais, que se originam em função de deficiências ou dificuldades de aprendizagem (Declaração de Salamanca, 1994), é uma oportunidade de rever conceitos e preconceitos a muito embutidos no senso comum, e também uma oportunidade de rever e substituir práticas educativas que acarretam em poucos resultados positivos. Dessa forma, considera-se importante retratar um pouco da visão dos professores que nela atuam e o que encontramos na literatura sobre o assunto.

O trabalho publicado por Leonel e Leonardo (2014) sobre a perspectiva dos professores a respeito da aprendizagem e desenvolvimento de alunos com deficiência intelectual, relata que esses professores observam "uma aprendizagem mais lenta, em outras palavras, é o aluno que aprende nesse ritmo (lento); com isso justifica-se o desenvolvimento baixo das expectativas tanto do professor quanto da escola" (2014, p. 548). Em contraponto, Facci (2004, p. 73) afirma que "a aprendizagem promove o desenvolvimento", nesse caso, devolve ao professor a responsabilidade "de transmitir os conhecimentos de forma sistematizada e, a partir de seu trabalho e da oferta de conhecimentos científicos, contribuir para o desenvolvimento do aluno" (LEONEL; LEONARDO, 2014).

Nesse sentido, observa-se uma ênfase nas dificuldades dos alunos, e não nas potencialidades que esses apresentam, logo, é importante reconsiderar o trabalho educativo e o papel da escola como ferramentas fundamentais para ocorrência da aprendizagem dos alunos com deficiência intelectual, conforme Vygotsky (2006, p. 115):

\footnotetext{
A aprendizagem não é, em si mesma, desenvolvimento, mas uma correta organização da aprendizagem da criança conduz ao desenvolvimento mental, ativa todo um grupo de processos de desenvolvimento, a esta ativação não poderia produzir-se sem a aprendizagem. Por isso, a aprendizagem é um momento intrinsecamente necessário e universal para que se desenvolvam na criança essas características humanas não naturais, mas formadas historicamente.
}

Ou seja, os momentos em sala de aula devem oportunizar tal processo de organização da aprendizagem, no entanto, os obstáculos apontados pelos profissionais da educação são mencionados em Facci (2004) onde afirma que as dificuldades enfrentadas pelos 
http://dx.doi.org/10.5902/1984686X61983

professores no processo de ensino e aprendizagem do aluno com DI, devem-se ao fato de eles não terem o conhecimento necessário para vencer os desafios, ou seja, o professor só poderá propagar o conhecimento e o saber se ele próprio houver tido acesso ao ensino e ao saber construído. Rossato e Leonardo (2014) continuam:

É tão natural o insucesso escolar dessas crianças que uma reversão dessa realidade representaria um fato inusitado? Nesta linha, nossas práticas revelam nossas concepções sobre o homem, sobre a sociedade, sobre a educação, sobre deficiência, e ao mesmo tempo, o quanto elas vão sendo cristalizadas, criando conformidade e alienação e tornando conveniente a manutenção de nossa sociedade no que tange aos papéis dos atores que a compõem e aos processos de exclusão (2014, p. 78).

Ao deparar-se com esta realidade, e a não conformidade a respeito disto, surge à iniciativa, um tanto inusitada que, de certa forma gerou estranheza, cogitar a busca de evidências de aprendizagem significativa em um contexto tão adverso como o apresentado, seria mesmo pertinente? Segundo a teoria de aprendizagem significativa proposta por David Ausubel (2003), a formação de novos conhecimentos mais complexos a partir da formação de uma rede de associações obtida de conhecimentos prévios do aluno, chamados por Ausubel et al (1980) de subsunçores. Esses elementos já presentes na estrutura cognitiva dos alunos funcionam como âncoras que vão ampliando e estabelecendo relações entre ideias e conceitos nos quais os novos conhecimentos vão sendo encaixados, resultando na aprendizagem significativa do aluno.

O conhecimento é significativo por definição. É o produto significativo de um processo psicológico cognitivo ("saber") que envolve a interação entre ideias "logicamente" (culturalmente) significativas, ideias anteriores ("ancoradas") relevantes da estrutura cognitiva particular do aprendiz (ou estrutura dos conhecimentos deste) e o "mecanismo" mental do mesmo para aprender de forma significativa ou para adquirir e reter conhecimentos (AUSUBEL et al, 1980, p.137).

A teoria da Aprendizagem Significativa propõe que a tarefa de aprendizagem deve relacionar, de forma não arbitrária e substantiva (não literal), uma nova informação a outros conceitos relevantes já existentes na estrutura cognitiva, e o aluno deficiente intelectual apresenta essa condição. Devemos considerar aqui que todos os alunos possuem conhecimentos previamente adquiridos, inclusive os alunos com DI, e é nesse ponto que estruturamos este trabalho.

Quando Ausubel et al (1980) considera as formas não arbitrárias e substantivas (não literais) para atingir a aprendizagem significativa, isto quer dizer que as relações cognitivas não carecem ser estritamente lógicas, e ao pé da letra. Isso significa que a ancoragem não 
http://dx.doi.org/10.5902/1984686X61983

segue especificamente uma lógica, limitada a uma maneira correta de acontecer, ela é única para cada indivíduo. Para Moreira (2011), na elaboração do novo conhecimento, as ligações cruzadas que representam ligações entre conceitos, em diferentes segmentos ou domínios do conhecimento, muitas vezes, evidencia saltos criativos por parte do estudante.

A sequência de atividades propostas e desenvolvidas durante a realização da UcEPS foi baseada na estrutura que está orientada para a descoberta (AUSUBEL, 2003) de uma relação de meio e fim, na busca da solução do problema. Esse tipo de abordagem, Ausubel (2003) conceitua como aprendizagem por descoberta. Deve-se considerar que a aprendizagem por descoberta envolve transformação, síntese, formulação de hipótese, argumentação, rearranjo, recombinação e integração.

Segundo Ausubel (2003, p. 78), o produto fenomenológico, fruto de uma aprendizagem por compreensão e idiossincrática, ou seja, os significados não estão nos objetos, nos materiais, nos signos, mas nos sujeitos, no aluno, no professor. Destaca-se que é ilusória a ideia que a aprendizagem significativa é a aprendizagem correta ou a que mais sensibiliza, visto que a partir de atribuição de significados, que estruturam-se na compreensão, através do compartilhamento de ideias (Hammel, Miyahara e Santos, 2019). Dessa forma, acredita-se ser pertinente a aplicação de uma sequência didática que tem por finalidade a aprendizagem significativa para alunos com DI, tendo em vista as demandas específicas de desenvolvimento de cada aluno, estes apresentam potencialidades que podem e devem ser destacadas e que permitem tal aprendizagem.

\section{Unidades compartilhadas de Ensino Potencialmente Significativas (UcEPS) como alternativa no ensino de jovens e adultos com DI}

Esta pesquisa caracteriza-se como um relato de experiência, que contou com a participação de duas turmas de EJA (Educação de Jovens e Adultos) de uma escola de Educação Básica, na modalidade de Educação Especial, do município de Turvo, no interior paranaense, com um total de 18 alunos, com idades entre dezessete e quarenta e cinco anos, todos com deficiência intelectual, dos quais dois têm Síndrome de Down.

Para melhor descrever a metodologia, recorre-se a Oliveira (2011), o qual estabelece critérios de classificação para a pesquisa, que nesse caso enquadra-se quanto aos objetivos em uma pesquisa exploratória, que para Zikmund (2000), são úteis para diagnosticar situações, explorar alternativas ou descobrir novas ideias. Descritos por Oliveira (2011) 
http://dx.doi.org/10.5902/1984686X61983

Esses trabalhos são conduzidos durante o estágio inicial de um processo de pesquisa mais amplo, em que se procura esclarecer e definir a natureza de um problema e gerar mais informações que possam ser adquiridas para a realização de futuras pesquisas conclusivas. Dessa forma, mesmo quando já existem conhecimentos do pesquisador sobre o assunto, a pesquisa exploratória também é útil, pois, normalmente, para um mesmo fato organizacional, pode haver inúmeras explicações alternativas, e sua utilização permitirá ao pesquisador tomar conhecimento, se não de todas, pelo menos de algumas delas (2011, p. 23).

Quanto à natureza da pesquisa, ajuste-se como qualitativa e quanto à escolha do objeto de pesquisa trata-se de um estudo de caso. Segundo Yin (2001), o estudo de caso é caracterizado pelo estudo complexo dos fatos objetos de investigação, permitindo um amplo e particularizado conhecimento da realidade e dos fenômenos pesquisados.

Um estudo de caso é uma investigação empírica que investiga um fenômeno contemporâneo dentro do seu contexto da vida real, especialmente quando os limites entre o fenômeno e o contexto não estão claramente definidos (YIN, 2001 p. 33).

Ainda, temos que a técnica de coleta de dados foi a observação e a técnica de análise dos dados foi análise de conteúdo. Bardin (1977) afirma que a análise de conteúdo possui duas funções básicas: função heurística - aumenta a prospecção à descoberta, enriquecendo a tentativa exploratória e função de administração da prova - em que, pela análise, buscam-se provas para afirmação de uma hipótese.

Um conjunto de técnicas de análise das comunicações visando a obter, por procedimentos, sistemáticos e objectivos de descrição do conteúdo de mensagens, indicadores (quantitativos ou não) que permitam a inferência de conhecimentos relativos às condições de produção/recepção (variáveis inferidas) dessas mensagens (BARDIN, 1977, p. 42).

A ideia de aplicar sequências didáticas durante as aulas surge quando uma professora, que tinha vários anos de experiência na Educação Básica e no Ensino Médio, é contratada para trabalhar na Educação Especial. Tendo já desenvolvido UEPS (Unidades de Ensino Potencialmente Significativas) Ihe ocorreu aplicar sequência semelhante com alunos com DI da etapa EJA.

No primeiro momento, com certa estranheza, mas com muito entusiasmo são aplicadas as primeiras UcEPS (Unidades compartilhadas de Ensino Potencialmente Significativas) e, observando o sucesso destas, organiza-se e aplica-se a UcEPS intitulada Coronavírus. A iniciativa emerge quando o assunto que toma crescente proporção nas mídias em geral no final do mês de fevereiro de 2020.

A partir desse momento a professora passa a trabalhar conteúdos de Português por meio da leitura e interpretação de textos informativos escritos, bem como, textos das mídias 
http://dx.doi.org/10.5902/1984686X61983

diversas como por exemplo, o Whatsapp, o Facebook, a televisão e os programas de rádio, considerando que os alunos ouvem a rádio local durante as aulas; Ciências, abordando conceitos de higiene e saúde e Arte, através da paródia da cirandinha com ênfase na prevenção do vírus.

Hammel, Miyahara e Santos (2019) ressaltam que ao elencar um tema e/ou conteúdo o professor considere que os conhecimentos recebidos hoje pelo aluno interfiram no seu cotidiano agora ou futuramente, que baseados nessas informações possam mudar, alterar, melhorar o seu redor. Escapando da velha prática de apresentar o conteúdo, exemplificar, exercitar e avaliar, retomando quando necessário, a aplicação da UcEPS tem, no decorrer da própria execução, elementos que viabilizam a aprendizagem significativa. Assim como a UEPS, esta sequência também está organizada em oito passos, não fixos, mas todos importantes, a diferença consiste exclusivamente na interdisciplinaridade que justifica o termo "compartilhada" presente na UcEPS.

Figura 1: Síntese das etapas da UEPS

1 - Definição de conceitos: tópicos a serem abordados que devem explicar como as informações serão declaradas para posteriormente servirem de base para construçăo dos conhecimentos.

2 - Investigação dos conhecimento prévio: elaborar situações que visem a explicação da estrutura cognitiva relevante.

3 - Situações problema introdutórias: utilizando estratégias diversificadas (vídeos, exemplos do cotidiano) para dar sentido aos novos conhecimentos.

4 - Diferenciação progressiva: deve-se partir dos conhecimentos mais gerais partir para os inclusivos.

5 - Complexidade: estruturar os conhecimentos através da apresentaçăo de novas situaçōes problemas em um nível mais alto de complexidade, diferenciação e abstraçăo.

6 - Reconciliação integrativa: retomar as características essenciais dos conteúdos através da apresentação de novos significados.

7 - Avaliação: registrar ao longo da interação todos os possíveis INDíCIOS de evoluções conceituais, denotando aprendizagens significativas.

8 - Efetividade: verificação do êxito da UEPS, através da avaliação de desempenho dos alunos denotada através da análise da progressiva evolução de um campo conceitual, enfatizando evidências contínuas e não em comportamentos finais.

Fonte: Os autores (2020) 
http://dx.doi.org/10.5902/1984686X61983

A figura 1 descreve resumidamente os oito passos seguidos na aplicação da sequência didática que é descrita no próximo item.

\section{A intervenção e os passos da UcEPS}

O objetivo da sequência proposta foi realizar uma atividade de reelaboração de conhecimentos pré-existentes e aquisição de novos conhecimentos a partir destes. Possui caráter cognitivo, motor, relacional e emocional, a fim de estabelecer novos objetos de aprendizagem. Oportunizou-se ainda outros elementos considerados relevantes como características particulares de cada aluno e do seu comportamento no desenvolver das atividades.

Com base nas etapas propostas por Moreira (2011), foi iniciada a sequência de atividades que abaixo estão representadas. Cabe reforçar que este trabalho foi realizado duas semanas antes do estabelecimento do distanciamento social e da suspensão das aulas, por isso a atividade proposta reforçou que pessoas que estiveram com alguém que veio da China deveriam ficar em alerta.

\section{UcEPS: "CORONAVÍRUS"}

1 - Definição de conceitos: do que se trata o coronavírus? Quais os cuidados de higiene que precisamos tomar? Como nos prevenir? Esse passo é exclusivo do professor, é a hora do planejamento, hora de organizar ideias e estratégias. Nesse caso, optou-se pela relevância do tema no contexto em que os alunos se encontram e o panorama mundial de pandemia.

\section{2 - Investigação dos conhecimentos prévios: o que é o CORONAVÍRUS?}

Após a acolhida dos alunos, a professora pergunta: vocês viram na TV, no Facebook, Whatsapp ou ouviram no rádio notícias sobre o CORONAVÍRUS?

Acolhe-se a fala dos alunos, muitos têm contribuições e a professora seleciona e dá ênfase às participações mais relevantes. Para Ausubel (2003), os conhecimentos prévios que os alunos trazem para a sala de aula são explicações funcionais para os objetos e fenômenos, e várias vezes pouco elaborados, esses conhecimentos precisam ser identificados e considerados pelo professor.

E a professora pergunta, vamos saber um pouquinho mais sobre esse assunto?

3 - Situações problema introdutórias: a família do vírus.

Nesse momento é entregue aos alunos uma informação previamente escolhida e impressa pela professora. Feito isso, a professora faz a leitura. Observa-se que existem 
http://dx.doi.org/10.5902/1984686X61983

palavras diferentes e difíceis, mas considera-se que é importante oportunizar aos alunos o aumento do léxico, ou seja, oportuniza-se o conhecimento do novo, do inesperado, isso proporciona curiosidade e estimula os alunos sua capacidade de novas aprendizagens. Moreira (2011) considera que o maior objetivo dessa interação envolvendo professor, estudante e materiais educativos é promover o compartilhamento de significados.

Quando a professora lê: "pertencentes à subfamília taxonômica Orthocoronavirinae da família Coronaviridae, da ordem Nidovirales" questiona os alunos: palavras difíceis? Vocês já tinham ouvido essas palavras? E acrescenta... viu, até o CORONAVíRUS tem família!

Aproveitando o ensejo, e no intuito que os alunos tivessem um pouco mais de entendimento do que se tratava, são questionados sobre seus sobrenomes, e um a um eles vão falando, então temos sobrenomes simples como Silva, Souza, e complicados como Schinaider, Sheroedher, entre outros, e assim como nós o coronavírus também pertence a uma família que tem um "sobrenome" bem difícil.

Retomando o texto enfatiza-se 0 fato desse tipo de vírus causar infecções respiratórias e pneumonia grave, por isso ele é tão perigoso. Terminada a leitura, pede-se que encontrem no texto a família do coronavírus, e a pintem com lápis de cor da sua preferência.

4 - Diferenciação progressiva: paródia cirandinha.

Hora de trabalhar as formas de contaminação e prevenção do vírus.

A paródia da Figura 2, é cantada duas ou três vezes para sensibilizar os alunos. Destaca-se que o fato de inserir uma paródia em um ritmo conhecido do aluno, gera-se resgate emocional e conforto cognitivo por estar presente na estrutura cognitiva dos mesmos. Logo após são entregues duas outras atividades.

A primeira, esclarece o que é um caso suspeito de coronavírus. Também é importante enfatizar o uso de máscaras pelos alunos, conscientizar que dessa forma cuidamos uns dos outros, e prevenimos o contágio. Libâneo (2013) escreve que diversas estratégias podem ser empregadas pelos professores para favorecer o desenvolvimento da criatividade no estudante em sala de aula. O objetivo maior é de fortalecer os traços de personalidade, autoconfiança, curiosidade, coragem, persistência e independência de pensamento no intuito de explorar novas situações e trabalhar com o que ainda é desconhecido, oportunizando e ajudando os alunos a se desvincular de bloqueios emocionais, como o 
http://dx.doi.org/10.5902/1984686X61983

medo de serem criticados ou o medo de errar, ou ainda sentimentos de inferioridade e insegurança.

Figura 2: Paródia

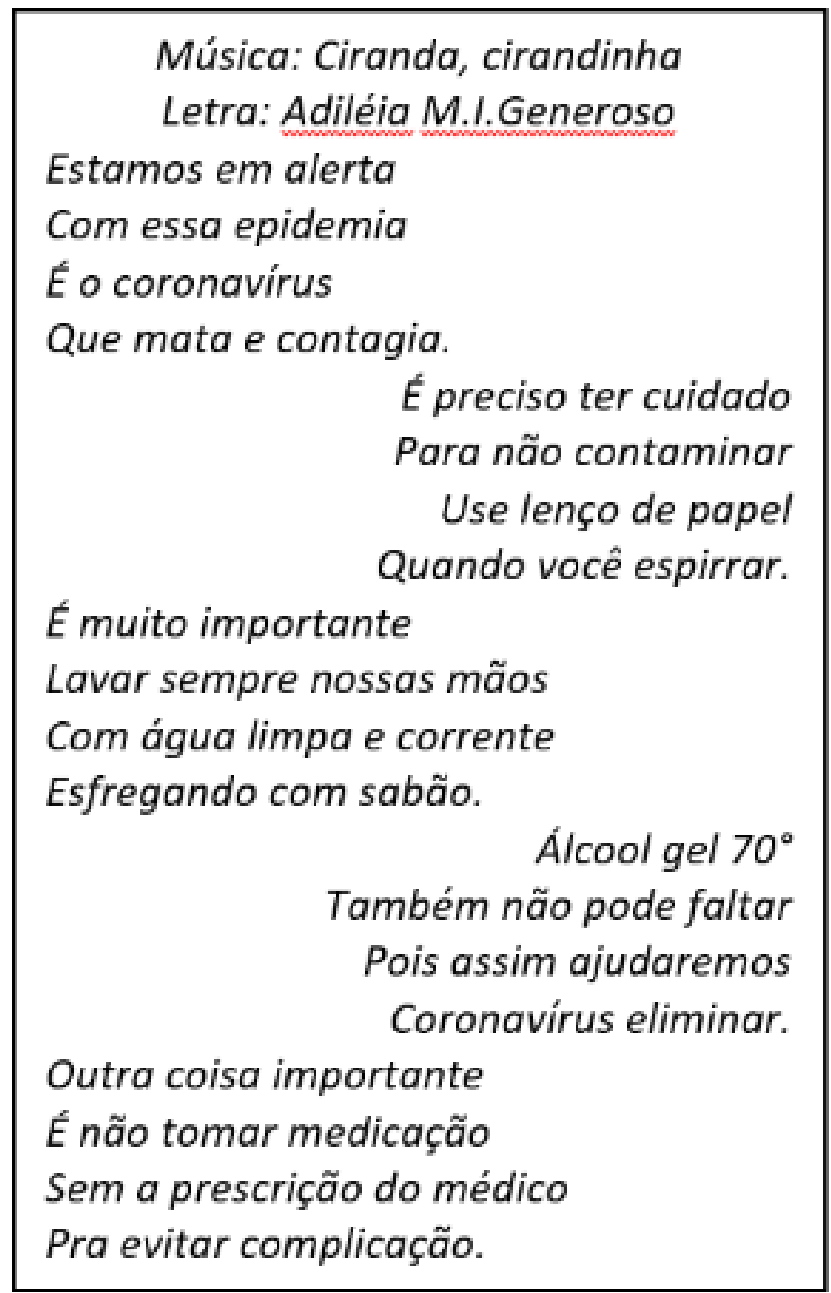

Fonte: Os autores (2020).

A segunda atividade apresentou situações ilustrativas do que mais devemos evitar, como beijos, abraços, apertos de mão. Após a leitura, os alunos utilizam diferentes texturas, materiais e cores para especificar situações impróprias. A professora reforçou ainda diferentes maneiras de cumprimentar as pessoas já que neste momento não devemos apertar as mãos.

Os alunos então levantaram e praticaram! Tocar com os cotovelos ou tocar com os pés. Este foi um momento de descontração e brincadeira.

5 - Complexidade: atividades

Neste passo os alunos tiveram acesso a atividades que oportunizam a leitura de imagens e o desenvolvimento da escrita. Primeiro, os alunos resolvem as frases 
enigmáticas, substituindo as imagens pelas correspondentes palavras. A correção foi realizada no quadro pelos próprios alunos para que todos pudessem comparar suas respostas e fazer as correções necessárias, se fosse o caso. Para Moreira (2001), na elaboração do novo conhecimento, as ligações cruzadas que representam ligações entre conceitos, em diferentes segmentos ou domínios do conhecimento, muitas vezes, evidencia saltos criativos por parte do estudante. Segundo Ausubel (2003), a presença de ligações cruzadas e consequente aparência ramificada, denotam uma estrutura cognitiva pobre e mapas repletos de ligações cruzadas indicam uma estrutura rica.

Essa atividade também permite o destaque de vários elementos importantes em tempos de epidemia ou pandemia, que é o caso. Por exemplo: lavar as mãos com sabão, utilizar álcool $70^{\circ}$ para limpar superfícies, tapar a boca ao tossir, utilizar lenço de papel e utilizar a máscara. Todas essas situações foram reforçadas oralmente pela professora, levando os alunos a comentarem sobre seus hábitos atuais e o que precisam melhorar, evitar ou mudar daqui em diante.

A segunda atividade desse passo pede que os alunos façam a correta leitura da imagem e completem adequadamente os quadros. O objetivo dela é observar as condições de leitura e escrita individual. Masini e Moreira (2009) esclarecem que a aprendizagem significativa é progressiva, os significados vão sendo captados e internalizados paulatinamente

\section{6- Reconciliação integrativa: hora de praticar.}

No sexto momento, é hora de praticar. Entende-se que falar sobre o assunto é bom, exemplificar é muito bom, mas praticar faz com que os elementos vistos e estudados adquiram maior estabilidade cognitiva, por isso a experimentação e a prática mostram-se bastante eficientes também na Educação Especial.

E esse foi objetivo do desenvolvimento das atividades propostas, estimular a autonomia, a capacidade de tomada de decisão assertiva nos cuidados de si e do outro.

7 - Avaliação: durante o desenvolvimento das atividades.

Os alunos foram observados durante o decorrer de toda unidade. E a professora fez as anotações necessárias e ao perceber alguma dificuldade, foi feita a retomada. Ao longo da interação e em diferentes momentos durante a realização das atividades foram observados indícios de evoluções conceituais, denotando aprendizagens significativas.

$A$ avaliação foi concomitante à realização e o desenvolvimento da sequência e proporcionou subsídios de análise e registro feitos posteriormente pela professora. 
Segundo Moreira (2011), UEPS somente será considerada exitosa se a avaliação do desempenho dos alunos fornecer evidências de aprendizagem significativa (captação de significados, compreensão, capacidade de explicar, de aplicar o conhecimento para resolver situações-problema). A aprendizagem significativa é progressiva, o domínio de um campo conceitual é progressivo; por isso, a ênfase em evidências, não em comportamentos finais.

\section{8 - Efetividade: verificação do êxito da UcEPS}

Segundo Santos et al (2018), todo estudante é capaz de aprender desde que o professor e a escola saibam organizar o processo de ensino e aprendizagem, que permitam a variação de metodologias e os trabalhos em grupo. Os mesmos autores acrescentam que não se faz educação inclusiva sem professores conhecedores da sua área de formação, uma formação pedagógica e também uma formação específica, continuada, são imprescindíveis para o sucesso do processo de ensino e aprendizagem.

Dessa forma, tem-se que a UcEPS cumpriu o proposto e ainda apresentou novos elementos, instigando o interesse a participação dos estudantes e oportunizando a retomada de conhecimentos prévios, a apresentação de novos conhecimentos, a reconciliação entre ambos e o estabelecimento de novas aprendizagens.

\section{Algumas ponderações}

Considera-se oportuno apresentar aos professores que atuam na modalidade de Educação Especial as UcEPS como mecanismo que pode aumentar as condições de ocorrência da aprendizagem significativa em alunos com DI.

Dessa forma, observa-se que sempre que aplicada uma sequência didática, inclusive a UcEPS, é pertinente examinar as potencialidades e fragilidades da mesma. É importante que ao analisarmos o desenvolvimento de uma Unidade de Ensino Potencialmente Significativa, "verifique-se se a mesma contemplou várias e diversificadas atividades na pretensão de atender as necessidades particulares de cada aluno" (HAMMEL, MIYAHARA e SANTOS, 2019), isso aumentará a possibilidade de ocorrência de uma aprendizagem significativa.

[...] se a UEPS, mesmo que sensivelmente, alcançou seu objetivo de possibilitar a turma uma aprendizagem que não fosse memorística, sem significado, onde o aluno tem a sensação de ser o centro do ensino, com valorização de seus conhecimentos prévios e a possibilidade de negociação constante de significados referentes aos conhecimentos científicos entre os pares e com o professor (BRUM, 2015, p. 71). 
http://dx.doi.org/10.5902/1984686X61983

Podemos fazer a verificação de êxito na implementação da UcEPS quando percebemos que a avaliação do desempenho dos alunos com DI foi baseada na análise da progressiva evolução de um determinado tema e/ou conteúdo, no caso da UcEPS, temos que as evidências foram contínuas e não baseadas apenas em comportamentos finais.

\section{Considerações finais}

Ao pensarmos na aprendizagem significativa de alunos com DI (deficientes intelectuais), alegamos que estes, apesar das limitações e exclusões, possuem potencialidades, e estas podem ser maximizadas a fim de alcançar uma aprendizagem que promove seu desenvolvimento e autonomia. A UcEPS (Unidade compartilhada de Ensino Potencialmente Significativa) com o tema "Coronavírus" oportunizou abordar um tema atual, pertinente no contexto mundial, e importante na conjuntura em que estão imersos os alunos com DI que frequentam a EJA.

As atividades propostas tiveram a pretensão de serem facilitadoras da aprendizagem significativa, mas reforça-se que é a maneira de aplicar e conduzir a realização das mesmas que podem as tornar exitosas. Elencando um tema bastante conveniente foi possível abordar as disciplinas de Português, Ciências e Arte. Trabalhando conteúdos como oralidade, escrita, leitura/escuta (compartilhada e autônoma), seres vivos e ambiente (higiene, saúde e prevenção), música (melodia e ritmo).

É justo apontar a importância do papel do professor. Tudo acontece em torno do que ele propor e por isso é tão pertinente rever as práticas no contexto de sala de aula, também no que tange a modalidade de Educação Especial, nesse caso dando prioridade ao desenvolvimento de estudos que viabilizem a aprendizagem significativa que, por sua vez, vai conduzir o indivíduo para maior autonomia e independência. A presença do professor em sala de aula justifica-se mais em função da sua atuação como mediador do conhecimento de forma que os alunos aprendam os saberes escolares em interação com o outro, e não apenas recebam-no passivamente, reforçando a metáfora de ensino bancário.

Reconhecendo e trabalhando na tentativa de diminuir as fragilidades apresentadas pelos alunos com DI, e buscando maneiras de incluí-lo, o objetivo maior é torná-lo capaz de participar ativamente da sociedade, e isso será possível desde que the seja dada a oportunidade de vivenciar ou, no mínimo, visualizar situações que o integrem à mesma. 
Buscando alternativas, inclusive tecnológicas, que minimizem tais dificuldades, o aluno pode tornar-se um cidadão dinâmico no contexto familiar, comunitário e social.

O papel atribuído à UcEPS aplicada aos 18 alunos com DI que frequentam a EJA, foi de mecanismo didático, metodológico, que abordou disciplinas e conteúdos previstos para esta etapa de ensino, oportunizou a interdisciplinaridade, valorizou os conhecimentos prévios dos alunos, promoveu a diferenciação progressiva e a reconciliação integrativa e ainda mostrou-se atual e pertinente no contexto individual, familiar, comunitário e social.

Mas como se pode afirmar que houve aprendizagem significativa destes alunos? Somando-se às observações anteriormente registradas, imposto distanciamento social e a suspensão das atividades na escola, a professora entrou em contato com os alunos, individualmente, via Whatsapp, para retomada remota das atividades e, perguntando como eles estavam, obteve respostas do tipo: "eu tô lavando a mão direitinho professora"; "eu pedi pra mãe compra álcool gel professora"; "eu não saio de casa, mas uso máscara quando vou sair". As falas acima foram transcritas literalmente, por esse motivo evidenciam-se a peculiaridade destas.

Quanto aos números de alunos que deram retorno positivo, dezesseis deles foi conseguido entrar em contato via Whatsapp, no caso do aluno que não possui celular, o contato foi feito com o familiar ou responsável que tem, outros dois não têm acesso à internet por morarem distantes da cidade, no interior do município.

Considera-se exitosa a aplicação da sequência didática (UcEPS) uma vez que promoveu mudanças no comportamento dos alunos, alterando seu estado anterior, vista a capacidade que os mesmos desenvolveram e aprimoraram de reconhecer a situação de pandemia e a necessidade de prevenir a contaminação e reconhecer os sintomas.

Encerrando este trabalho temos que, apesar dos satisfatórios e empolgantes resultados encontrados, julga-se que há muito ainda a ser estudado e pesquisado em relação à aprendizagem significativa e a possibilidade de sua ocorrência no que tange a deficiência intelectual.

\section{Referências}

AUSUBEL, D. P. Aquisição e retenção de conhecimentos: uma perspectiva cognitiva. Lisboa: Plátano, 2003.

AUSUBEL, D. P.; NOVAK, J. D.; HANESIAN, H. Psicologia educacional. Rio de Janeiro: Interamericana, 1980. 
BARDIN, L. Análise de conteúdo. Lisboa: Edições 70, 1977.

BRASIL. Declaração de Salamanca e linha de ação sobre necessidades educativas especiais. 2. ed. Brasília, DF: Corde, 1997.

BRUM, W. P. Análise de uma Unidade de Ensino Potencialmente Significativa no Ensino de Matemática: uma investigação na apresentação do tema volume do paralelepípedo a partir da ideia de eclusa. Aprendizagem Significativa em Revista, v 5 (2), p. 50-74, 2015.

FACCI, M. G. D. A periodização do desenvolvimento psicológico individual na perspectiva de Leontiev, Elkonin e Vigotski. Cad. Cedes, Campinas, v.24, n.62, p.64-81, 2004. Disponível em: http://www. cedes.unicamp.br. Acesso em: 03 fev. 2020.

GENEROSO, A. M. I. Sobre coronavírus - Ensino Fundamental 1. Mistura de alegria, 2020. Disponível em: https://misturadealegria.blogspot.com/2020/02/sobre-coronavirusensino-fundamental-1.html. Acesso em: 07 de mar. de 2020.

HAMMEL, C.; MIYAHARA, R. Y.; SANTOS, S. A. Uma UEPS com enfoque CTSA no ensino de Física: geração, produção e consumo de energia elétrica. Experiências em Ensino de Ciências, v.14, n.1, p. 256-270, 2019.

HAMMEL, C.; MIYAHARA, R. Y.; SANTOS, S. A. O estudo do espectro eletromagnético: o ensino através de uma sequência didática - UEPS. Dynamis, v.25, p. 23-34, 2019.

MASINI, E. A. F.; MOREIRA, M. A. Aprendizagem significativa: condições para ocorrência e lacunas que levam a comprometimentos. São Paulo: Vetor Editora. 2008.

MOREIRA, M. A. Unidades de Enseñanza Potencialmente Significativas-UEPS. Aprendizagem Significativa em Revista, Porto Alegre, v.1, n.2, p.43-63, 2011.

MOREIRA, M. A. Aprendizagem significativa: a teoria de David Ausubel. São Paulo: Centauro, 2001.

LIBÂNEO, J.C. Didática. 2ª ed. São Paulo: Cortez, 2013.

LEONEL, W.H.S.; LEONARDO, N.S.T. Concepções de professores da educação especial (APAEs) sobre a aprendizagem e desenvolvimento do aluno com deficiência intelectual: um estudo a partir da teoria Vigotskiana. Revista Brasileira de Educação Especial, Marília, v.20, n.4, p.541-554, 2014.

OLIVEIRA, M. F. de. Metodologia científica: um manual para a realização de pesquisas em Administração. Catalão, 2011. Disponível em:

https://files.cercomp.ufg.br/weby/up/567/o/Manual_de_metodologia_cientifica_-

_Prof_Maxwell.pdf. Acesso em: 17 de jul. de 2020.

ROSSATO, S.; LEONARDO, N. A deficiência intelectual na concepção de educadores da educação especial: contribuições da psicologia histórico cultural, Revista Brasileira de Educação Especial, v.17, n.1, p.71-86, 2011. 
SANTOS, Â. M. dos; CARVALHO, P. S; ALECRIM, J. L. O ensino de física para jovens com deficiência intelectual: uma proposta para facilitar a inclusão na Escola Regular.

Revista Educação Especial, v.32, p.1-19, 2018.

VYGOTSKI, L.S. Aprendizagem e desenvolvimento intelectual na idade escolar. In: VYGOTSKI, L.S.; LURIA, A. R.; LEONTIEV, A. N. (Org.). Linguagem, desenvolvimento e aprendizagem. São Paulo: Ícone. 2006.

YIN, R. K. Estudo de caso: planejamento e métodos. 2.ed. Porto Alegre: Bookman, 2001.

ZIKMUND, W. G. Business research methods. 5.ed. Fort Worth, TX: Dryden, 2000.

(i) (9)

This work is licensed under a Creative Commons Attribution-NonCommercial 4.0 International (CC BY-NC 4.0) 